\title{
КЛЮЧЕВЫЕ ПРИНЦИПЫ, ТРЕБОВАНИЯ И ПРОЦЕДУРЫ ОПЕРАТИВНОГО И ПРЕВЕНТИВНОГО ИНСТРУМЕНТАРИЯ РЕАЛИЗАЦИИ ВНУТРЕННЕГО ФИНАНСОВОГО КОНТРОЛЯ
}

\author{
(C) 2021 Петров Александр Михайлович \\ доктор экономических наук, профессор Департамента бизнес-аналитики \\ Финансовый университет при Правительстве Российской Федерации, Россия, Москва \\ профессор кафедры бухгалтерского учета и налогообложения \\ Российский экономический университет им. Г. В.Плеханова, Россия, Москва \\ E-mail: palmi@inbox.ru
}

Эффективное исполнение федеральных проектов, в части расходования выделенных на них средств, опирается на оперативный и превентивный инструментарий внутреннего финансового контроля. В статье рассматриваются ключевые принципы и требования оперативного и превентивного инструментария реализации внутреннего финансового контроля

Ключевые слова: бюджетные нарушения, внутренний финансовый контроль, федеральный проект, отраслевой риск, ключевые индикаторы риска.

С целью построения эффективного оперативного и превентивного инструментария внутреннего финансового контроля (ВФК) в рамках расходования средств на федеральные проекты уточним основные принципы, соблюдение которых является необходимым условием (рисунок 1). Раскроем содержание каждого из представленных принципов.

Принцип законности предполагает, что каж-

дый работник службы внутреннего финансового контроля должен руководствоваться законодательством Российской Федерации и локальными нормативными документами проверяемого субъекта хозяйствования.

Принцип ответственности предусматривает ответственность каждого сотрудника службы ВФК за совершаемые им действия или бездействие при обнаружении правонарушений и

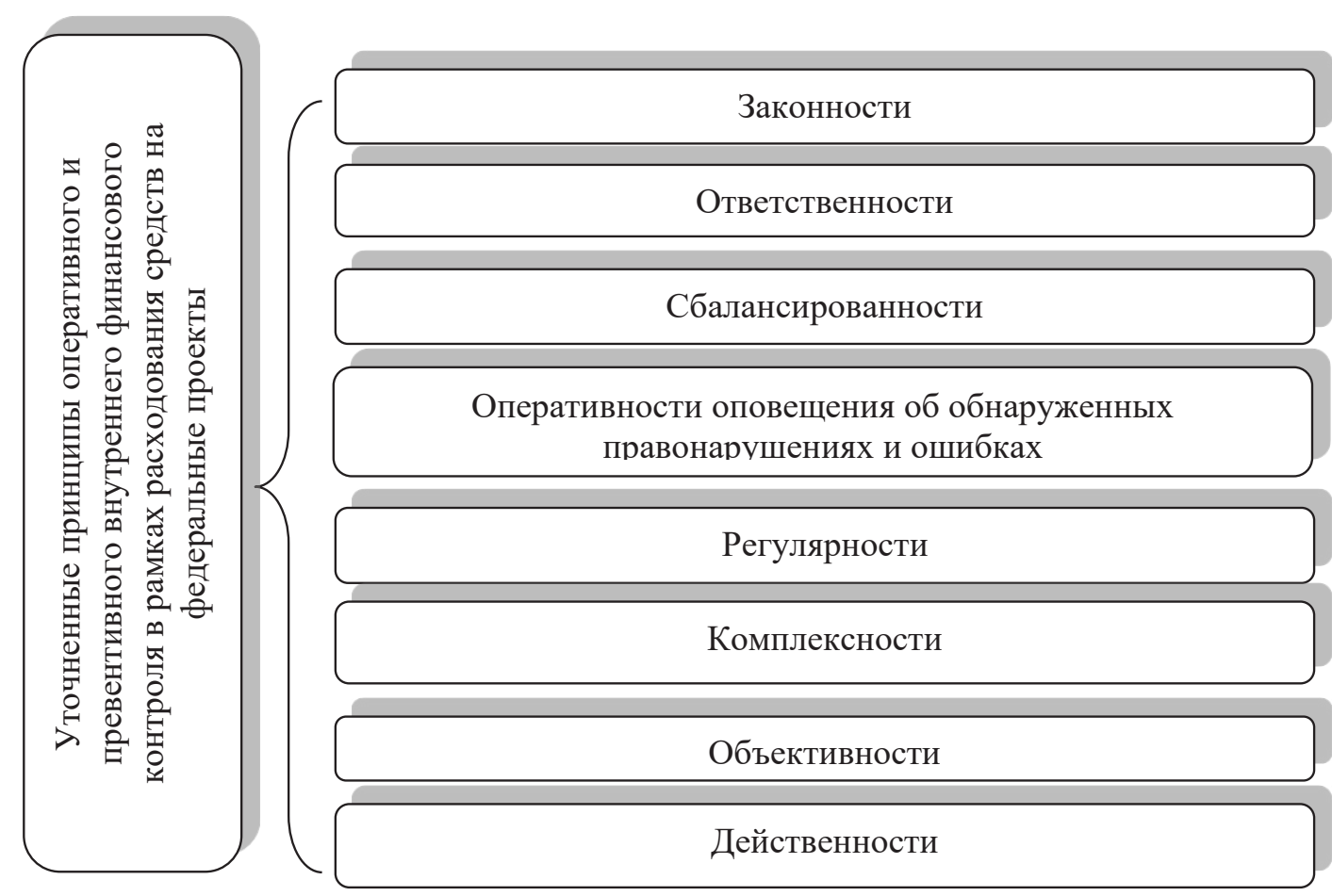

Puc. 1. Уточненные принципы оперативного и превентивного внутреннего финансового контроля в части расходования бюджетных средств, выделенных на федеральные проекты 
ошибок. Безответственное выполнение функций внутренними контролерами приводит к отрицательным последствиям. В связи с этим, именно ответственность персонала способствует формированию эффективной системы ВФК.

Принцип сбалансированности предусматривает, что при выполнении контрольных функций необходима сбалансированность между средствами контроля и правами субъекта контроля.

Принцип оперативности оповещения об обнаруженных правонарушениях и ошибках предполагает, что работник, выполняющий контрольные мероприятия при выявлении нарушений, недочетов и ошибок должен своевременно извещать о них органы управления.

Принцип регулярности предполагает проведение внутреннего финансового контроля на регулярной основе.

Принцип комплексности предусматривает, что при проведении внутреннего финансового контроля необходимо охватывать все направления, задействованные в рамках выполнения федеральных проектов.

Принцип объективности предполагает, что все внутренние контролеры при выполнении своих функций оценивают объекты контроля беспристрастно, объективно.

Принцип действенности гласит, что процедуры ВФК должны быть действенными, эффективными, экономически оправданными.

Эффективность внутреннего финансового контроля во многом зависит от соблюдения основных требований. В этой связи уточним ключевые требования оперативного и превентивного ВФК в рамках расходования бюджетных средств, выделенных на федеральные проекты, и представим их на рисунке 2.

Требование заинтересованности администрации состоит в заинтересованности органов управления в эффективности и повышении качества внутреннего финансового контроля.

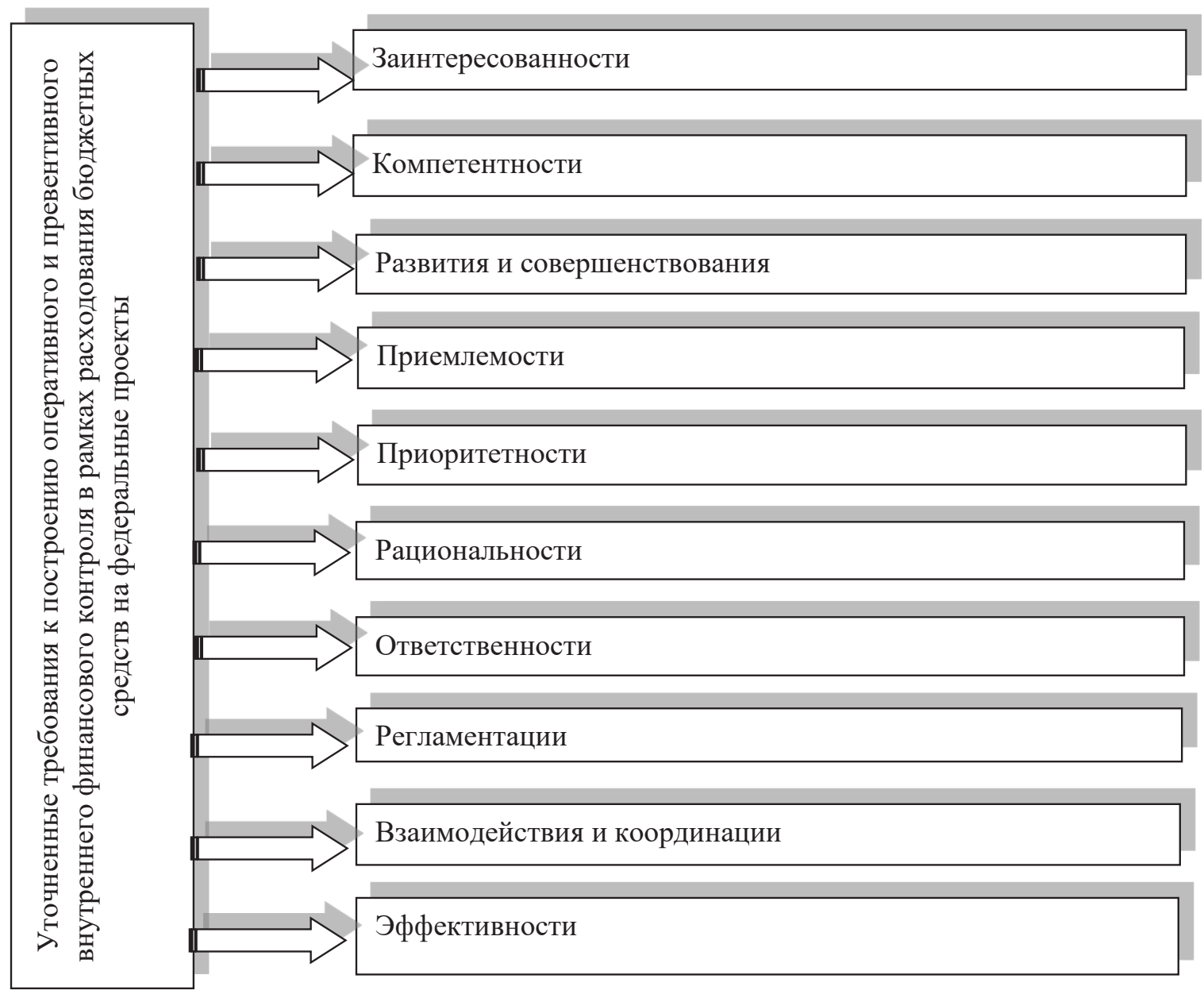

Puc. 2. Уточненные ключевые требования оперативного и превентивного внутреннего финансового контроля в части расходования бюджетных средств, выделенных на федеральные проекты 
Требование компетентности работников внутреннего финансового контроля предполагает высокий уровень профессионализма и честность работников внутреннего финансового контроля.

Требование развития и совершенствования направлено на постоянное развитие системы внутреннего финансового контроля, которое обусловлено изменением законодательства, влиянием внешних и внутренних факторов.

Требование приемлемости методологии внутреннего финансового контроля состоит в возможности реализации всех методов и процедур внутреннего финансового контроля на практике.

Требование приоритетности предусматривает ранжирование участников с высокой степенью риска и проверки их в первую очередь.

Требование рациональности предполагает, что все применимые процедуры, методы и мероприятия должны быть рациональными и целесообразными.

Требование ответственности состоит в том, чтобы каждый работник службы внутреннего финансового контроля осознавал собственную ответственность при выполнении профессиональных функций.

Требование регламентации заключается в том, что все основные контрольные функции, процедуры и мероприятия должны быть официально оформленными и соответствовать установленным локальным документам.

Требование взаимодействия и координации ориентировано на взаимодействии всех структурных подразделений и участников федеральных проектов.

Требование эффективности предполагает, что все используемые методы и процедуры внутреннего финансового контроля, а также разработанные мероприятия должны быть эффективными и обоснованными.

Внутренний оперативный финансовый контроль направлен на обеспечение обратной связи между прогнозными показателями, определенными первоначальными планами и фактиче- скими данными, полученными в результате выполнения проектов. Он должен реализоваться на протяжении всего периода выполнения федеральных проектов, как с позиции распределителей бюджетных средств, так и их получателей.

K основным методам оперативного внутреннего финансового контроля в рамках расходования средств на федеральные проекты необходимо отнести: анализ, индукцию, дедукцию, обследование, мониторинг, проверку, опрос, тестирование и др. Необходимо отметить, что данные методы могут применяться как распорядителями, так и получателями средств в рамках расходования средств на федеральные проекты [2].

В рамках нашего исследования под процедурами внутреннего финансового контроля будем понимать действия, которые направлены на снижение рисков, влияющих на достижение целей и задач при реализации федеральных проектов. Основные виды процедур превентивного ВФК в рамках расходования средств на федеральные проекты представлены нами на рисунке 3.

Превентивные контрольные процедуры направлены на предотвращение наступления нежелательных последствий, снижение рисков не достижения целей посредством превентивных процедур, которое достигается запретом нежелательных, недопустимых действий до их совершения. В процессе реализации оперативного финансового контроля в рамках расходования бюджетных средств на федеральные проекты необходимо выполнять следующие действия: определять фактическое состояние выполнения проектов; сравнивать фактические суммы расходов, связанных с выполнением федеральных проектов с планируемыми; оценивать отклонения, превышающие предельно допустимый уровень и выявлять их причины; проверять правильность оформления всей документации, связанной с операциями по выполнению федеральных проектов и расходованию бюджетных средств и т.п. 
Процедуры превентивного внутреннего финансового контроля в рамках расходования средств на федеральные проекты

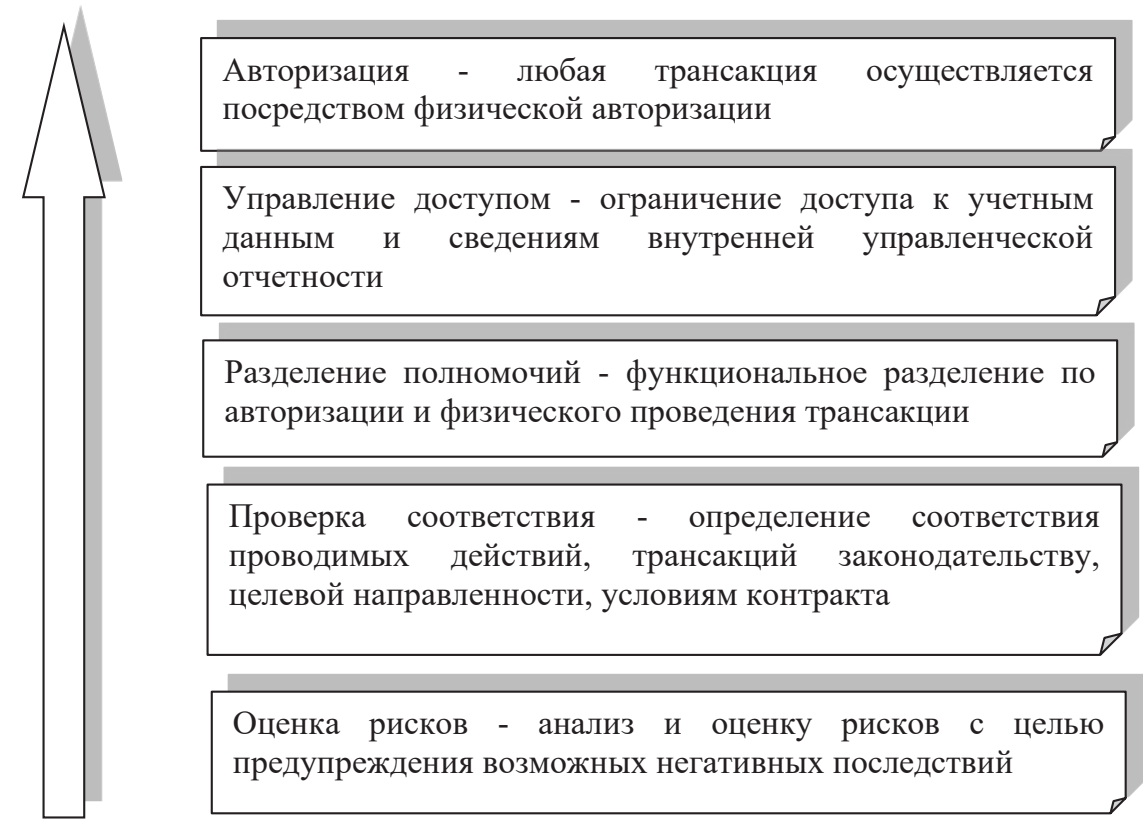
Puc. 3. Процедуры превентивного внутреннего финансового контроля
в рамках расходования средств на федеральные проекты

\section{Библиографический список}

1. Петров А. М., Бурцева К. Ю. К вопросу организации внутреннего финансового контроля в рамках расходования средств на федеральные проекты // Экономические науки. - 2020. - № 188. - С. 113-119.

2. Петров, А.М. Оперативный и превентивный инструментарий реализации внутреннего финансового контроля в рамках расходования средств на федеральные проекты // Экономические науки. - 2020. - № 185. C. 169-178.

3. INTERNAL CONTROL MANUAL FOR FEDERAL GRANTS [Электронный ресурс]. - URL: https://www.ipsk12.net/ cms/lib/MA02212674/ Centricity/Domain/275/IPS\%20MANUAL\%20FOR\%20FEDERAL\%20GRANTS-Final\%20 Version\%205.4.17.pdf (дата обращения: 10.03.2020).

4. Петрова О.А. «Бухгалтерский учет обеспечения исполнения контрактных обязательств в России» / Экономические науки 2021, № 9, стр. 232-234

5. Петрова О.А. «Цифровизация консолидированной финансовой отчетности в страховом бизнесе» / Экономические науки 2021, № 10

6. Петрова О.А. «Проблемы развития рынка факторинговых услуг» / Экономические науки 2021, № 10

7. Chen T.-C., Zhu W.-W., Jiao Z.-K., Petrov A.M. Creep-fatigue lifetime estimation of snagcu solder joints using an artificial neural network approach / Mechanics of Advanced Materials and Structures. 2021.

8. Shabbir M.S., Siddiqi A.F., Yapanto L.M., TonkovE.E., Poltarykhin A.L., Pilyugina A.V., PetrovA.M., Foroughi A., Valiullina D. A. Closed-loop supply chain design and pricing in competitive conditions by considering the variable value of return products using the whale optimization algorithm / Sustainability. 2021. T. 13. № 12.

9. Kavitha M., Mahmoud Z. H., Kishore K. H., Petrov A. M., Lekomtsev A., Iliushin P., Zekiy A. O., Salmani M. Application of Steinberg model for vibration lifetime evaluation of SN-AG-CU-based solder joints in power semiconductors / IEEE Transactions on Components, Packaging and Manufacturing Technology. 2021. T. 11. № 3. C. 444-450.

10. Shnaider V.V., PipkoE.G., PetrovA.M. Current information needs of passenger and freight transportation enterprises in Russia / Вестник Национальной академии наук Республики Казахстан. 2020. № 4 (386). С. $348-$ 353.

11. Petrov A., Tolmachev M., Shlychkov D., Basova M., Turishcheva T. Analysis of current trends of employment diversification at the international level: case study of pharmacy industry / Systematic Reviews in Pharmacy. 2020. T. 11. № 12. C. $1383-1390$. 